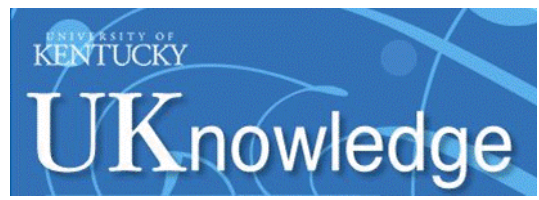

University of Kentucky

UKnowledge

\title{
Limited Association Between Perceived Control and Health- Related Quality of Life in Patients with Heart Failure
}

\author{
Teesta Banerjee \\ Stanford University \\ Kyoung Suk Lee \\ University of Wisconsin - Madison \\ Steven R. Browning \\ University of Kentucky, srbrown@uky.edu \\ Claudia Hopenhayn \\ University of Kentucky, claudia.hopenhayn@uky.edu \\ Susan C. Westneat \\ University of Kentucky, swest1@email.uky.edu
}

See next page for additional authors

Follow this and additional works at: https://uknowledge.uky.edu/epidemiology_facpub

Part of the Cardiology Commons, and the Nursing Commons

Right click to open a feedback form in a new tab to let us know how this document benefits you.

\section{Repository Citation}

Banerjee, Teesta; Lee, Kyoung Suk; Browning, Steven R.; Hopenhayn, Claudia; Westneat, Susan C.; Biddle, Martha J.; Arslanian-Angoren, Cynthia; Eastwood, Jo-Ann; Mudd, Gia; and Moser, Debra K., "Limited Association Between Perceived Control and Health-Related Quality of Life in Patients with Heart Failure" (2014). Epidemiology and Environmental Health Faculty Publications. 24.

https://uknowledge.uky.edu/epidemiology_facpub/24

This Article is brought to you for free and open access by the Epidemiology and Environmental Health at UKnowledge. It has been accepted for inclusion in Epidemiology and Environmental Health Faculty Publications by an authorized administrator of UKnowledge. For more information, please contact UKnowledge@lsv.uky.edu. 


\section{Limited Association Between Perceived Control and Health-Related Quality of Life in Patients with Heart Failure}

Digital Object Identifier (DOI)

https://doi.org/10.1097/JCN.0b013e31828b2b23

\section{Notes/Citation Information}

Published in Journal of Cardiovascular Nursing, v. 29, no. 3, p. 227-231.

Copyright @ 2014 Wolters Kluwer Health I Lippincott Williams \& Wilkins

The document available for download is the authors' post-peer-review final draft of the article.

\section{Authors}

Teesta Banerjee, Kyoung Suk Lee, Steven R. Browning, Claudia Hopenhayn, Susan C. Westneat, Martha J. Biddle, Cynthia Arslanian-Angoren, Jo-Ann Eastwood, Gia Mudd, and Debra K. Moser 


\title{
Limited Association Between Perceived Control and Health- Related Quality of Life in Patients with Heart Failure
}

\author{
Teesta Banerjee, MBBS, MPH [Clinical Researcher], \\ Department of Oncology, Cancer Genetics Program, Stanford School of Medicine
}

Kyoung Suk Lee, PhD, RN, MPH [Assistant professor], University of Wisconsin-Madison School of Nursing, Madison, WI, USA

Steven R Browning, PhD [Assistant Professor], University of Kentucky College of Public Health, Lexington, KY, USA

Claudia Hopenhayn, PhD [Associate Professor], University of Kentucky College of Public Health, Lexington, KY, USA

Susan Westneat, MA, University of Kentucky, College of Nursing, Lexington, KY, USA

Martha J. Biddle, PhD, APRN [Assistant Professor], University of Kentucky, College of Nursing, Lexington, KY, USA

Cynthia Arslanian-Engoren, PhD, RN [Associate Professor], University of Michigan, School of Nursing, Ann Arbor, MI, USA

Jo-Ann Eastwood, PhD [Assistant professor], University of California-Los Angeles, School of Nursing, Los Angeles, CA, USA

Gia Mudd, PhD, RN, MPH [Assistant professor], and University of Kentucky, College of Nursing, Lexington, KY, USA

Debra K Moser, DNSc, RN, FAAN [Professor]

University of Kentucky, College of Nursing, Lexington, KY, USA

\begin{abstract}
Heart failure (HF) is a chronic, incurable, debilitating condition, in which a major management goal is improvement in health-related quality of life (HRQOL). Although patients with HF have to learn how to live with HF, the process of adaptation to HF is not simple. Patients with HF often are overwhelmed by their therapeutic regimen and frustrated with inability to perform social and leisure activities that they used to enjoy. ${ }^{1,2}$ The illness trajectory of HF, which is hard to predict and differs from patient to patient, is a source of uncertainty or loss of control. ${ }^{3,4}$ In qualitative studies, HF patients' experiences were described as "feeling imprisoned in illnesses"5 or "feeling powerless."
\end{abstract}

Despite advances in medical management in HF, older adults who have HF experience worse HRQOL than those who do not have $\mathrm{HF}^{7,8}$ or who have other chronic illnesses. ${ }^{8}$ Impaired HRQOL is associated with adverse outcomes, such as increased rates of

Corresponding author: Kyoung Suk Lee, PhD, RN, MPH, Assistant professor, University of Wisconsin-Madison School of Nursing, Address: University of Wisconsin-Madison School of Nursing, H6/342 Clinical Sciences Center, 600 Highland Ave., Madison, WI53792-2455, kslee4@wisc.edu, Tel: 608-263-5272.

Publisher's Disclaimer: This is a PDF file of an unedited manuscript that has been accepted for publication. As a service to our customers we are providing this early version of the manuscript. The manuscript will undergo copyediting, typesetting, and review of the resulting proof before it is published in its final citable form. Please note that during the production process errors may be discovered which could affect the content, and all legal disclaimers that apply to the journal pertain. 
hospitalizations and mortality. ${ }^{9}$ It is essential to identify factors influencing HRQOL in HF in order to develop strategies to improve patients' HRQOL.

Perceived control (i.e., the belief that one has resources needed to cope with negative events and the ability to positively influence consequences of those negative events) is potentially an important factor in an individual's HRQOL, because of its inverse relationship to anxiety and depression, major predictors of HRQOL. ${ }^{10-13}$ Perceived control is essential to successful adjustment to stressful events and improvement in HRQOL among individuals after myocardial infarction and heart transplant. ${ }^{14,15}$ In post-cardiac transplantation patients, ${ }^{14}$ there is a positive relationship between perceived control and HRQOL among female heart transplant recipients. However, the relationship between perceived control and HRQOL has not been studied in patients with HF. Therefore, the purpose of this study was to determine whether perceived control is an independent predictor of HRQOL in patients with HF.

\section{Methods}

\section{Study design, sample, and setting}

A cross-sectional study was conducted among patients recruited from HF clinics in three Midwestern states in the United States. The conduct of the study was approved by Institutional Review Boards at each study site. Nurse practitioners or physicians in the clinics identified eligible patients and referred them to trained research nurses. After a detailed explanation about the study, patients who agreed to participate gave signed informed consent.

Patients were invited to participate if they had a documented medical diagnosis of HF from either systolic or diastolic dysfunction, were free of myocardial infarction within three months prior to enrollment, and able to speak and read English. Patients who had lifethreatening comorbid conditions (e.g., end-stage renal diseases and cancer other than skin cancer) or obvious cognitive impairment that limited their ability to provide informed consent or complete questionnaires were excluded.

Measures

Health-related quality of life-The Minnesota Living with HF Questionnaire (MLHFQ) was used to measure HRQOL. ${ }^{16}$ The MLHFQ consists of 21 items rated by patients using a 6-point Likert scale $(0=$ no impact to $5=$ serious impact). Scores of each item are summed to yield a total score, which can range from 0 to 105. A higher score reflects worse HRQOL. A change or a difference in score of $>5$ on this instrument is considered clinically meaningful. ${ }^{17}$

Perceived control-Perceived control was measured using the Control Attitude ScaleRevised (CAS-R). ${ }^{11}$ The CAS-R is an 8-item instrument where items are rated on a scale from 0 (totally disagree) to 5 (totally agree). Total scores can range from 8-40, with a higher score denoting higher perceived control. The validity and reliability of the CAS-R has been supported in a number of cardiac populations, including HF. ${ }^{11}$

Psychological status-Psychological status was evaluated using the Brief Symptom Inventory (BSI) subscales for depressive symptoms (six items) and anxiety (six items). ${ }^{18}$ For each subscale, patients are asked to rate how much they have been bothered by each symptom item in the past seven days using a five-point scale $(0=$ "not at all" to $4=$ "extremely"). Total scores of each subscale scores are determined by averaging item ratings. The possible range of each subscale is from 0 to 4 , with higher scores indicating 
higher levels of depressive symptoms or anxiety. There are published mean scores in healthy individuals to indicate high and low levels of depressive symptoms ( $\leq 0.28 \mathrm{vs.}>0.28$ ) and anxiety ( $\leq 0.35$ vs. $>0.35$ ). ${ }^{18}$ The validity and reliability of the BSI have been demonstrated. ${ }^{18,19}$

Demographic and clinical variables-Age, gender, marital status, etiology of HF, New York Heart Association (NYHA) functional class, and prescribed medications were collected via patient interview and medical records review. Total comorbidity burden was measured with the Charlson Comorbidity Index via patient interview. ${ }^{20}$ NYHA functional class was determined by trained research nurses through structured patient interview. The Charlson Comorbidity Index ${ }^{20}$ can range from $0-30$, with a higher score indicating a higher levels of burden from comorbid diseases.

\section{Data Analyses}

Data analyses were conducted using SAS 9.3 (Cary, North Carolina). Pearson's correlation coefficients $(r)$ were used to examine the linear associations of HRQOL with perceived control and psychological status (i.e., depressive symptoms and anxiety). Linear regression modeling was used to examine the relationship between perceived control and HRQOL. A univariate linear regression model was used to examine the association between perceived control and HRQOL. Hierarchical multiple linear regression then was used to examine the independent contribution of perceived control to HRQOL after adjusting for the following covariates: age, gender, ethnicity, marital status, total comorbidity burden, NYHA functional class, etiology of HF, and psychological status. Two model blocks were tested. In the first block, covariates were regressed on scores of HRQOL. In the second block, perceived control was added to the variables included in the first block. Model assumption (e.g., linearity) and multi-collinearity were evaluated. Covariates included in the model were identified from the literature.

\section{Results \\ Sample characteristics}

The study sample consisted of 423 patients with HF (Table 1). Approximately half of patients $(47 \%)$ were 65 years or older with a range of 24 to 97 years. Patients were primarily men, white, and in NYHA functional class III and IV. Mean scores of perceived control was $26.1 \pm 5.1$, indicating relatively high levels of perceived control. When comparing our results with the mean reported scores of the BSI, ${ }^{18} 66.0 \%$ and $46.5 \%$ of patients in this study had levels of depressive symptoms and anxiety, respectively, higher than the reported non-patient mean.

\section{Correlations of health-related quality of life, perceived control, and psychological status}

HRQOL was significantly correlated with perceived control, depressive symptoms, and anxiety. Scores of HRQOL (higher scores indicate worse HRQOL) were negatively correlated with scores of perceived control $(r=-0.49, p<0.01,95 \%$ confidence interval [CI] $-0.56--0.41)$, meaning that worse HRQOL were related to lower levels of perceived control. Scores of HRQOL were positively correlated with scores of depressive symptoms $(r=0.64, p<0.01,95 \%$ CI $0.59-0.70)$ and anxiety $(r=0.64, p<0.01,95 \%$ CI $0.57-0.69)$, indicating that worse HRQOL were related to higher levels of depressive symptoms and anxiety. There were moderate levels of correlation between scores of perceived control and scores of depressive symptoms $(r=-0.46, p<0.01,95 \% \mathrm{CI}-0.53-0.38)$ and anxiety $(r=$ $-0.44, p<0.01,95 \% \mathrm{CI}-0.52-0.36$ ) indicating that higher levels of perceived control were associated with lower levels of depressive symptoms and anxiety. 


\section{Association between perceived control and health-related quality of life}

In univariate linear regression, perceived control explained $23.9 \%$ of the variance in HRQOL (unstandardized $\beta=-2.34$; standardized $\beta=-0.49$; $p$-value $<0.001$ ). In hierarchical linear regression (Table 2), sociodemographic, clinical variables, and psychological status explained 53.6\% of the variance in HRQOL. Adding perceived control to the model explained an additional $1.4 \%$ of the variance in HRQOL. Higher perceived control scores were associated with lower HRQOL scores, indicating that higher levels of perceived control were associated with better HRQOL ( $p$-value $<0.001$ ). Marital status (married or cohabitating vs. single/divorced/widowed), total comorbidity burden score, NYHA functional class (III/IV vs. I/II), depressive symptoms, and anxiety also predicted HRQOL.

\section{Discussion}

In this study, we examined the relationship between perceived control and HRQOL in patients with HF. We found that higher levels of perceived control were strongly associated with better HRQOL in univariate analysis, but this relationship was strongly attenuated after controlling for known factors associated with HRQOL. The variance in HRQOL explained by the addition of perceived control to a model containing demographic, clinical and psychological covariates was small (1.4\%).

There have been many efforts to understand HRQOL in HF and identify its determinants to enhance HRQOL. Heo and colleagues ${ }^{21}$ asked HF patients to define HRQOL. In this qualitative study, patients reported that they had a good HRQOL despite limitations in their daily lives due to HF; a good HRQOL meant being able to pursue happiness and have fulfilling relationships with others, rather than the mere absence of psychological distress. Given that HRQOL involves patients' active efforts to have a positive perspective to their lives, a sense of control appeared to be one component that contributed to maintenance of a good HRQOL. ${ }^{21}$

Despite the apparent importance of perceived control to HRQOL evident in the qualitative study by Heo and colleagues, ${ }^{21}$ we found a significant, yet weak relationship between perceived control and HRQOL in patients with HF. The relationship between perceived control and HRQOL in this study was attenuated after adding covariates to the regression model. The unadjusted $\beta$ coefficient of perceived control $(-2.34)$ in the univariate linear regression model was decreased by $68.5 \%$, compared to the unadjusted $\beta$ coefficient of perceived control $(-0.74)$ in the hierarchical linear regression model after adjusting for covariates. This finding suggests that covariates included in the model may partially mediate the relationship between perceived control and HRQOL.

Given the strong relationship between higher perceived control and both lower anxiety and lower depression in this and other studies, ${ }^{10,11,15}$ we postulate that psychological status may mediate the association between perceived control and HRQOL in this study (Figure 1). Perceived control plays an important role in psychological adjustment in individuals facing stressful events. Among patients who had experienced a cardiac event, perceived control was a significant determinant of psychological recovery (i.e., lower levels of depression, anxiety, and hostility over time). ${ }^{15}$ Similarly, HF patients with high perceived control had significantly less emotional distress than patients with low perceived control. ${ }^{10}$ Therefore, it is possible that perceived control indirectly influences HRQOL via psychological status in patients with HF.

There are limitations to note. Majority of the sample in this study was white and younger, and had less comorbidity burden, which limits the generalizability of findings in this study to the HF population. The cross-sectional, observational design limits causal inference of 
relationships between HRQOL and perceived control. However, we used valid and reliable instruments with a large number of patients from multiple cardiology clinics in the three Midwestern states.

\section{Conclusions}

As perceived control is a modifiable factor unlike intrinsic personality characteristics, interventions to enhance perceived control may be promising to improve HRQOL. However, we found only a weak relationship between perceived control and HRQOL when considered in the presence of demographic, clinical, and psychological factors. The result of this study suggests a possible mediation effect of psychological status on the association between perceived control and HRQOL in patients with HF; however, more studies are needed to support this suggested relationship among perceived control, psychological status, and HRQOL.

\section{Acknowledgments}

Funding acknowledgement: NIH \# R01 NR008567 from the National Institute of Nursing Research and a Center grant from NIH National Institute of Nursing Research \# 1P20NR010679. The content is solely the responsibility of the authors and does not necessarily represent the official views of the National Institute of Nursing Research or the National Institutes of Health.

\section{References}

1. Yu DS, Lee DT, Kwong AN, Thompson DR, Woo J. Living with chronic heart failure: a review of qualitative studies of older people. J Adv Nurs. 2008 Mar; 61(5):474-483. [PubMed: 18261056]

2. Jeon YH, Kraus SG, Jowsey T, Glasgow NJ. The experience of living with chronic heart failure: a narrative review of qualitative studies. BMC Health Serv Res. 2010; 10:77. [PubMed: 20331904]

3. Brannstrom M, Ekman I, Norberg A, Boman K, Strandberg G. Living with severe chronic heart failure in palliative advanced home care. Eur J Cardiovasc Nurs. 2006; 5(4):295-302. [PubMed: 16546447]

4. Bosworth HB, Steinhauser KE, Orr M, Lindquist JH, Grambow SC, Oddone EZ. Congestive heart failure patients' perceptions of quality of life: the integration of physical and psychosocial factors. Aging Ment Health. 2004; 8(1):83-91. [PubMed: 14690872]

5. Ekman I, Ehnfors M, Norberg A. The meaning of living with severe chronic heart failure as narrated by elderly people. Scand J Caring Sci. 2000; 14(2):130-136. [PubMed: 12035276]

6. Martensson J, Karlsson JE, Fridlund B. Female patients with congestive heart failure: how they conceive their life situation. J Adv Nurs. 1998; 28(6):1216-1224. [PubMed: 9888366]

7. Ekman I, Fagerberg B, Lundman B. Health-related quality of life and sense of coherence among elderly patients with severe chronic heart failure in comparison with healthy controls. Heart \& Lung. 2002; 31(2):94-101. [PubMed: 11910384]

8. Lesman-Leegte I, Jaarsma T, Coyne JC, Hillege HL, Van Veldhuisen DJ, Sanderman R. Quality of Life and Depressive Symptoms in the Elderly: A Comparison Between Patients With Heart Failure and Age- and Gender-Matched Community Controls. J Card Fail. 2009; 15(1):17-23. [PubMed: 19181289]

9. Kato N, Kinugawa K, Seki S, et al. Quality of Life as an Independent Predictor for Cardiac Events and Death in Patients With Heart Failure. Circ J. 2011; 75(7):1661-1669. [PubMed: 21532181]

10. Dracup K, Westlake C, Erickson VS, Moser DK, Caldwell ML, Hamilton MA. Perceived control reduces emotional stress in patients with heart failure. J Heart Lung Transpl. 2003; 22(1):90-93.

11. Moser DK, Riegel B, McKinley S, et al. The Control Attitudes Scale-Revised: psychometric evaluation in three groups of patients with cardiac illness. Nurs Res. 2009; 58(1):42-51. [PubMed: 19092554]

12. Calfee CS, Katz PP, Yelin EH, Iribarren C, Eisner MD. The influence of perceived control of asthma on health outcomes. Chest. 2006; 130(5):1312-1318. [PubMed: 17099005] 
13. Barez M, Blasco T, Fernandez-Castro J, Viladrich C. Perceived control and psychological distress in women with breast cancer: a longitudinal study. J Behav Med. 2009; 32(2):187-196. [PubMed: 18815877]

14. Evangelista LS, Moser D, Dracup K, Doering L, Kobashigawa J. Functional status and perceived control influence quality of life in female heart transplant recipients. J Heart Lung Transpl. 2004; 23(3):360-367.

15. Moser DK, Dracup K. Psychosocial recovery from a cardiac event: the influence of perceived control. Heart \& lung. 1995; 24(4):273-280. [PubMed: 7591794]

16. Rector TS, Kubo SH, Cohn JN. Patients' self-assessment of their congestive heart failure. Part 2: Content, reliability and validity of a new measure. The Minnesota Living with Heart Failure questionnaire. Heart Fail. 1987; 3:198-209.

17. Rector TS, Tschumperlin LK, Kubo SH, et al. Use of the Living With Heart Failure questionnaire to ascertain patients' perspectives on improvement in quality of life versus risk of drug-induced death. J Card Fail. 1995; 1(3):201-206. [PubMed: 9420652]

18. Derogatis LR, Melisaratos N. The Brief Symptom Inventory: an introductory report. Psychol Med. 1983; 13(3):595-605. [PubMed: 6622612]

19. Morlan KK, Tan SY. Comparison of the Brief Psychiatric Rating Scale and the Brief Symptom Inventory. J Clin Psychol. 1998; 54(7):885-894. [PubMed: 9811126]

20. Charlson ME, Pompei P, Ales KL, MacKenzie CR. A new method of classifying prognostic comorbidity in longitudinal studies: development and validation. J Chronic Dis. 1987; 40(5):373383. [PubMed: 3558716]

21. Heo S, Lennie TA, Okoli C, Moser DK. Quality of life in patients with heart failure: ask the patients. Heart \& lung. 2009; 38(2):100-108. [PubMed: 19254628] 


\section{What's New and Important}

- We found only a weak relationship between perceived control and HRQOL when considered in the presence of demographic, clinical, and psychological factors.

- Given the strong relationship between perceived control and psychological factors, the result of this study suggests a possible mediation effect of psychological status on the association between perceived control and HRQOL in patients with HF.

- More research is needed to examine whether perceived control indirectly influences HRQOL via psychological status in patients with HF. 


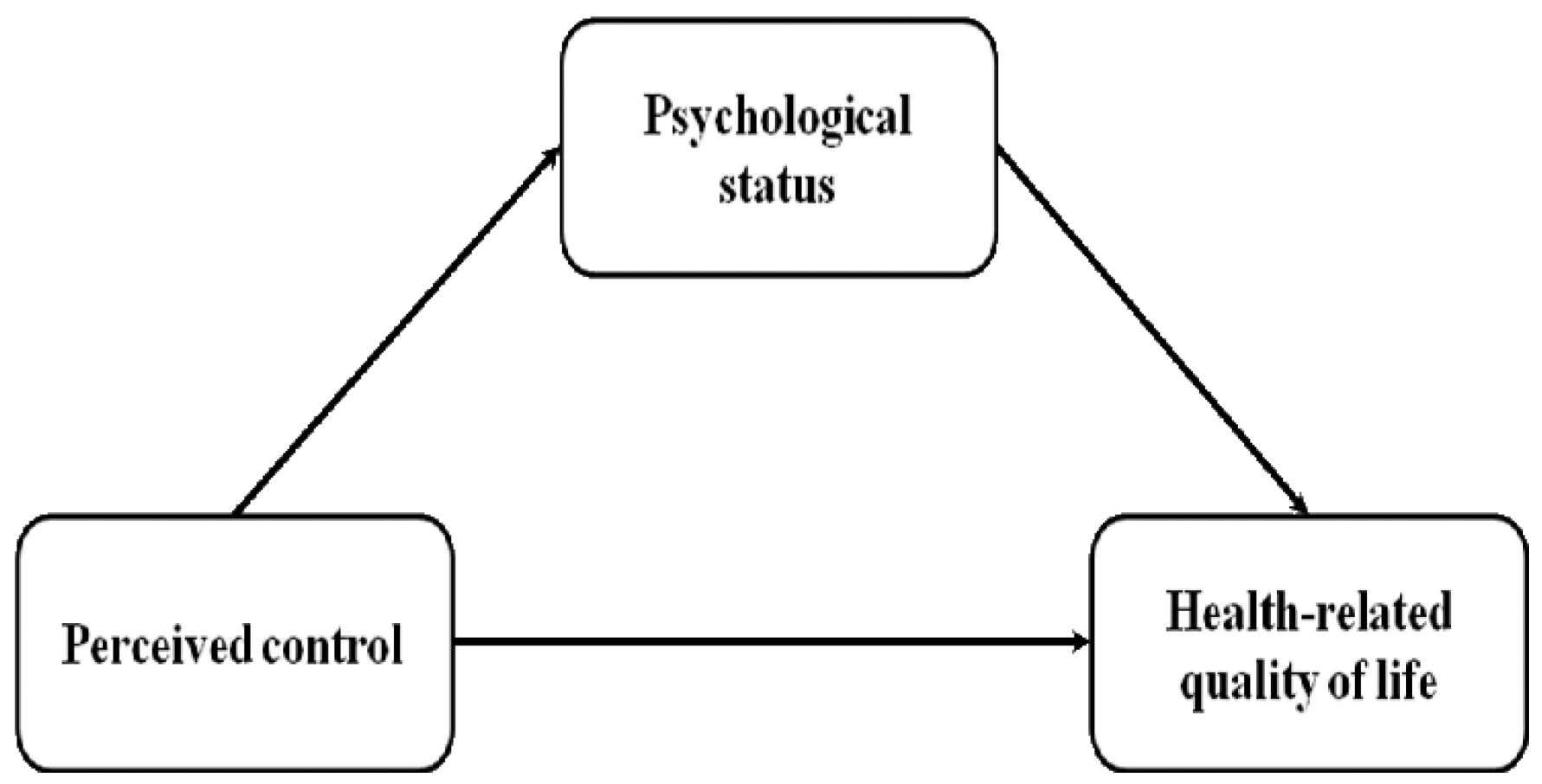

Figure 1.

Conceptual model of potential relationships among perceived control, psychological status, and health-related quality of life 


\section{Table 1}

Sample characteristics $(\mathrm{N}=423)$

\begin{tabular}{lc}
\hline & Mean \pm SD or N (\%) \\
\hline Age, years & $63 \pm 12$ \\
\hline Gender & $283(66.9 \%)$ \\
Male & $140(32.7 \%)$ \\
Female & \\
\hline Marital Status & $146(35.1 \%)$ \\
Single/divorced/widowed & $270(64.9 \%)$ \\
Married/co-habitating & \\
\hline Ethnicity & $242(57.2 \%)$ \\
White & $181(42.8 \%)$ \\
Minority & $182(43.0 \%)$ \\
\hline NYHA class & $241(57.0 \%)$ \\
I/II & $3.1 \pm 1.8$ \\
\hline III/IV & $297(70.2 \%)$ \\
\hline Charlson Comorbidity Index & $0.7 \pm 0.7$ \\
\hline Ischemic etiology of HF & $0.8 \pm 0.8$ \\
\hline Psychological factors & \\
Perceived control & \\
Health-related quality of life & $44.1 \pm 24.5$ \\
Anxiety & \\
\hline Depressive symptoms & \\
\hline Medications & \\
\hline
\end{tabular}

Note. NYHA=New York Heart Association; HF= Heart Failure; ACEI = angiotensin converting enzyme inhibitor; ARB = angiotensin receptor blocker 
